\title{
Book Review Beyond Repair: Mayan Women's Protagonism in the Aftermath of Genocidal Harm
}

\author{
Autumn Kirkendall, Anjali Dutt, $\mathrm{PhD}^{2}$ \\ ${ }^{1}$ Psychology, University of Cincinnati, ${ }^{2}$ Psychology, University of Cincinnati (OH) \\ Keywords: community psychology, book review, genocide, mayan women, protagonism \\ https://doi.org/10.35844/001c.11890
}

Journal of Participatory Research Methods

Vol. 1, Issue 1, 2020

Crosby, A., \& Lykes, M. (2019). Beyond Repair?: Mayan Women's Protagonism in the Aftermath of Genocidal Harm. New Brunswick, Camden; Newark, New Jersey; London: Rutgers University Press. doi:10.2307/j.ctvscxr3t

As we enter into the third decade of the $21^{\text {st }}$ century the number of enduring national and international conflicts and global crises that threaten human well-being are constant reminders to community researchers of the need to identify and practice methodologies that confront and address injustice. Where contemporary and emergent threats are frequent focuses of both media headlines and individual consciousness, it is necessary to consider connections between these threats and historical legacies of colonization and white supremacy culture. Moreover, it is essential to ensure that the voices, concerns, and well-being of members of communities who have been disadvantaged under these systems are heard, prioritized, and amplified when seeking to address past injustice and mitigate future conflict and threat. Researchers seeking to practice methodologies that are driven by these aims must honor the agency of marginalized community members, without neglecting how the harm of disenfranchisement shapes individual and collective subjectivity. Beyond Repair: Mayan Women's Protagonism in the Aftermath of Genocidal Harm offers powerful illustration of methods and concepts central to this goal, and is valuable reading to anyone involved in community-based research related to transitional justice, human rights, and feminist social change.

Some the most valuable contributions this book makes to community-based research are the use of the concept of protagonism in understanding the agency of women who have experienced great harm, the continuous attention to historical and diverse ecological contexts, and the thoughtful discussion of the role, positionality, and commitment of intermediaries working collaboratively on this research and justice project. The book is an examination of Mayan women's agency through processes to explore reparations for the harm they experienced during the 36 years of armed conflict and genocidal violence perpetrated by the Guatemalan state from 1960-1996. Specifically, the book follows 54 Q'eqchi', Kaqchikel, Chuj, and Mam women who survived multiple forms of violence during the war period, and their involvement in transitional 
justice efforts and feminist participatory action research aimed toward redress. Rather than portraying the women as mere victims of harm, participants in research, or individuals disconnected from social and historical context, Crosby and Lykes, use the concept of protagonism. In doing so, they emphasize that the 54 women are shaped by the stories of their past, and are actively constructing new narratives of what it means to be Mayan Women in a multitude of evolving contexts. The concept of protagonism both honors agency without minimizing previous and recurring harm, and is a meaningful consideration for community-based researchers and activists working in contexts of community disenfranchisement.

Through careful attention to historical and socio-cultural context, the authors avoid portraying protagonists as a homogenous group. In Chapter 1: "Documenting Protagonism", context is explored as the history and cultural background of the protagonists. Although the protagonists are grouped together by their general shared experience as survivors of the state-sponsored violence, the women come from different regions with different histories, socio-economic status, cultures, and experiences both during and following the war. The protagonists' differing community contexts are important to emphasize to express the diversity within shared experience. Furthermore, in Chapter 2: "Recounting Protagonism", context is further examined as the place of truth telling, an essential element of the work for redress. Depending on the context of time and place, the process and content of truth telling changes and requires different elements. Methodologically, recognizing the impact of context on truth telling is important because it affirms that recounting information can change based on the purpose or audience for whom the story is being recounted This attention to context is also valuable to recognize in feminist participatory action research because it affirms multiple truths within one story. When considering the complexity of agency and disenfranchisement, researchers are encouraged to deeply assess context in the methodology because this highlights areas where protagonists have more agency and areas where they do not, and how agency may be expressed or inhibited differently in different contexts.

The role and positionality of intermediaries are also discussed as crucial to the methodology of this eight-year research project, and offer important consideration for readers. The authors consider themselves intermediaries along with, "Mayan, ladinx, and transnational activists, interpreters, feminists, lawyers, psychologists, and researchers" (p. 3). Each of these roles are significant in the development and telling of the protagonists' narratives, and in the larger goal to seek justice and reparations. In Chapter 5: "Accompanying Protagonism", the authors describe the positionalities of the intermediaries and the challenges they encountered. While always important, this was a particularly necessary reflection process when considering differences in nationality, culture, and language among and between intermediaries and the protagonists. As part of the research, the authors also examined underlying assumptions held by intermediaries by having them engage in creative arts 
projects similar to ones done with the protagonists. Through this process, the authors were able to compare the art projects of the intermediaries to projects of the protagonists. This illuminates differences in perspectives, specifically how intermediaries see the issues differently from the protagonists. The result is a powerful examination of how intermediaries may support or disrupt agency for the protagonists, and an important consideration for anyone engaged in community-based research and action

Experiences and change do not happen in isolation and the interactions that occur will shape the outcome and retelling of experience. What is most powerful about this work is the attention to dialogical creation and transformation through all phases of the research and reparations process. The protagonists, setting, intermediaries, and audiences are all changing and evolving, which is always the case yet infrequently acknowledged in most research processes. Recognizing the impact of relationships through research and partnership through change acknowledges that the line between observed, observer, and assistant is quite blurry. The deep and thorough attention to context, agency, change, and exchange among all aspects and people involved in quests for justice makes this book is a valuable read for community-based researchers seeking to contribute to just transformation through their work. 